\title{
RESEARCH
}

Open Access

\section{MASTL induces Colon Cancer progression and Chemoresistance by promoting Wnt/ $\beta$-catenin signaling}

Srijayaprakash Babu Uppada', Saiprasad Gowrikumar', Rizwan Ahmad', Balawant Kumar', Bryan Szeglin,4, Xi Chen ${ }^{5}$, J. Joshua Smith ${ }^{3,4}$, Surinder K. Batra ${ }^{1,2}$, Amar B. Singh ${ }^{1,2,6}$ and Punita Dhawan ${ }^{1,2,6^{*}}$

\begin{abstract}
Background: Chemotherapeutic agents that modulate cell cycle checkpoints and/or tumor-specific pathways have shown immense promise in preclinical and clinical studies aimed at anti-cancer therapy. MASTL (Greatwall in Xenopus and Drosophila), a serine/threonine kinase controls the final G2/M checkpoint and prevents premature entry of cells into mitosis. Recent studies suggest that MASTL expression is highly upregulated in cancer and confers resistance against chemotherapy. However, the role and mechanism/s of MASTL mediated regulation of tumorigenesis remains poorly understood.
\end{abstract}

Methods: We utilized a large patient cohort and mouse models of colon cancer as well as colon cancer cells to determine the role of Mastl and associated mechanism in colon cancer.

Results: Here, we show that MASTL expression increases in colon cancer across all cancer stages compared with normal colon tissue $(P<0.001)$. Also, increased levels of MASTL associated with high-risk of the disease and poor prognosis. Further, the shRNA silencing of MASTL expression in colon cancer cells induced cell cycle arrest and apoptosis in vitro and inhibited xenograft-tumor growth in vivo. Mechanistic analysis revealed that MASTL expression facilitates colon cancer progression by promoting the $\beta$-catenin/Wnt signaling, the key signaling pathway implicated in colon carcinogenesis, and up-regulating anti-apoptotic proteins, $\mathrm{BCl}-\mathrm{xL}$ and Survivin. Further studies where colorectal cancer (CRC) cells were subjected to 5-fluorouracil (5FU) treatment revealed a sharp increase in MASTL expression upon chemotherapy, along with increases in $\mathrm{Bcl}-\mathrm{xL}$ and Survivin expression. Most notably, inhibition of MASTL in these cells induced chemosensitivity to 5FU with downregulation of Survivin and Bcl-xL expression.

Conclusion: Overall, our data shed light on the heretofore-undescribed mechanistic role of MASTL in key oncogenic signaling pathway/s to regulate colon cancer progression and chemo-resistance that would tremendously help to overcome drug resistance in colon cancer treatment.

Keywords: Colon cancer, Wht signaling and MASTL

\footnotetext{
* Correspondence: punita.dhawan@unmc.edu

'Department of Biochemistry and Molecular Biology, University of Nebraska

Medical Center, Omaha NE-68022, USA

${ }^{2}$ Buffet Cancer Center, University of Nebraska Medical Center, Omaha, NE,

USA

Full list of author information is available at the end of the article
}

(c) The Author(s). 2018 Open Access This article is distributed under the terms of the Creative Commons Attribution 4.0 International License (http://creativecommons.org/licenses/by/4.0/), which permits unrestricted use, distribution, and reproduction in any medium, provided you give appropriate credit to the original author(s) and the source, provide a link to the Creative Commons license, and indicate if changes were made. The Creative Commons Public Domain Dedication waiver (http://creativecommons.org/publicdomain/zero/1.0/) applies to the data made available in this article, unless otherwise stated. 


\section{Background}

Loss of cell-cycle control, a key regulatory aspect of normal growth, is a hallmark of neoplastic growth and malignancy, including in CRC. It is remarkable that due to the deregulation of cell cycle control, cancer cells evade programmed cell death despite accumulation of the genomic instabilities that would normally make them prime targets for apoptosis and cause them to divide rapidly. Unfortunately, currently available therapeutic drugs aimed at controlling the cell cycle in cancer cells have lacked the therapeutic index required to achieve a robust response against cancer cells while having little or no cytotoxic effect on normal cells. Thus, one of the strategy might be to target cell-cycle regulatory features distinctive to tumor cells.

In this regard, cell cycle kinases play a key role in promoting cell cycle progression through its different phases. Among these kinases, MASTL (named Greatwall in Xenopus and Drosophila) was identified recently and is now demonstrated to be important for mitosis, especially the G2/M checkpoint. More specifically, MASTL kinase activity prevents cells from premature entry into mitosis, and therefore minimizes chromosomal mis-segregation. To promote the G2/M transition, MASTL inhibits PP2A activity by phosphorylating ARPP19 and a-endosulfine (ENSA). As would be expected, genetic depletion of MASTL in young mice compromised survival, and this was due to severe proliferation defects [1]. MASTL expression, however, also helps to regulate recovery following DNA damage and inhibiting MASTL has been demonstrated to be beneficial for DNA damage-based therapies [2]. In line with known significance of these traits in malignant growth, upregulated expression of MASTL has been reported in breast, head, and neck cancers and is correlated with aggressive clinico-pathological features [2]. Moreover, a causal role for MASTL in resistance against anti-cancer therapies has been demonstrated using cell lines derived from initial and recurrent tumors of head and neck squamous cell carcinoma [3]. These studies suggest a critical role for MASTL in oncogenic growth and tumorigenesis. However, a causal association of MASTL in regulating colon cancer growth and progression and its potential role in resistance to conventional therapy, a critical factor in unrelenting patient death, remains an area of active investigation.

In this study, we demonstrate, using a comprehensive investigative scheme, a significant upregulation of MASTL expression in stage-specific manner in CRC progression and an inverse correlation with patient survival. We further show its causal significance in cancer progression and resistance to anti-CRC therapy. Mechanistically, we provide strong evidence for a novel role for MASTL in regulating $\mathrm{Wnt} / \beta$-catenin signaling to modulate $\mathrm{c}-\mathrm{Myc}$ and Survivin expression in promoting colon cancer. Overall these data identify MASTL as a novel therapeutic target in limiting colon cancer malignancy and reducing death from the disease.

\section{Methods \\ Cell culture, plasmids and transfection}

The human colon cancer cell lines HCT116, SW620, SW480, HT29, DLD-1, CaCo2, Ls174T, and IEC-6 cells were obtained from ATCC (Manassas, VA, USA) and cultured in RPMI-1640 containing 10\% fetal bovine serum and $1 \%$ antibiotic and antimycotic (thermoFisher). Cells were transfected as described previously using effectene reagent [4]. Mastl-knockdown cell population was selected using puromycin $(1 \mathrm{mg} / \mathrm{ml})$. The activated $\beta$-catenin (S33Y) mutant was described previously [5].

\section{Human tissue, microarray platforms and statistical analysis}

RNA from human samples was hybridized to Affymetrix Human Genome U133 Plus 2.0 GeneChip Expression Array.The protocols and procedures for the procurement of human tissue samples and details of the microarray platforms and statistical analysis have been described previously $[6,7]$.

\section{Immunoblot, immunohistochemistry and immunofluorescence analysis}

These analyses were performed using the standard protocols as described before [4]. Anti-MASTL Antibody (clone 4F9, MABT372, EMD Millipore), anti-E-cadherin antibody (BD transduction laboratories, USA), $\beta$-catenin (BD transduction laboratories, USA), GSK3beta (Cell Signaling Technology, Danvers, MA,USA), p-GSK3beta (Cell Signaling Technology, Danvers, MA,USA) Bcl-xL (Cell Signaling Technology), Survivin (Cell Signaling Technology) and anti-b- actin (Sigma, St. Louis, MO), were used for immunoblotting.

\section{Cell proliferation MTT assay and soft agar assay}

To assess cell proliferation, MTT assay was performed as described previously [7]. Anchorage-independence growth assay were used to determine the growth potential of MASTL knockdown cells as described previously [7].

\section{Oncogenic Array}

Oncogenic array analysis was performed using proteome profiler human $\mathrm{xl}$ oncology array kit (R\&D Systems, Minneapolis, MN)) as per manufacturer's instructions.

\section{Invasion assay}

Invasive potential of cells was measured in transwell filter insert with $8.0 \mu \mathrm{m}$ pore polycarbonate membrane (Corning) coated with Matrigel (BD, Franklin Lakes, NJ, USA) as described previously [7]. 


\section{Edu proliferation}

The 5-ethynyl-2'-deoxyuridine (EdU), a thymidine analogue, is incorporated into cellular DNA during DNA replication [8]. The incorporated EdU can be detected through a reaction between ethynyl group of EdU and a fluorescent azide in a copper-catalyzed [3+2] cycloaddition ("Click" reaction) using Click-iT ${ }^{\mathrm{Tn}}$ EdU imaging kit (Invitrogen, Carlsbad, CA) as per manufacturer protocol.

\section{Caspase-3 activity assay}

CaspACE $^{\mathrm{mm}}$ Assay System (Promega Corp., Madison, WI) was used to detect caspase-3 activity as per manufacturer protocol.

\section{Annexin V-fluorescein isothiocyanate/ propidium iodide staining}

We used the Hoechst/annexin V-fluorescein isothiocyanate (FITC)/ propidium iodide (PI) triple staining detection system to assess cell apoptosis. FITC Annexin V Apoptosis Detection Kit II (BD Biosciences, San Jose, CA) was used as per the manufacturer's instructions.

\section{RNA extraction and real-time RT-PCR}

Total RNA was extracted using RNeasy Plus Mini Kit (QIAGEN) according to manufacturer instructions as described [7].

\section{Cell cycle analysis}

Transfected cells were harvested and plated in six-well plates and cultured for $72 \mathrm{~h}$ in serum-free medium after which cells were treated with RO3306 (Sigma, St. Louis, MO), a CDK1 inhibitor for $16 \mathrm{~h}$. After $16 \mathrm{~h}$, media was replaced with fresh media and cells were grown for $1 \mathrm{~h}$, and then fixed and cell cycle analysis was carried out. The percentage of cells in G0/G1, S, and G2/M phases of the cell cycle was determined using flow cytometer (FACS Calibur, BD Biosciences, San Jose, CA) after PI staining.

\section{Xenograft-tumor studies}

All animal experiments were conducted with the approval of the Institutional Animal Care and Use Committee (IACUC) of UNMC. The tumorigenicity of cells under study was assessed using subcutaneous flank inoculation of $1 \times 10^{6}$ cells in 6 -week-old athymic nude mice. Animals were assessed for 5 weeks after the inoculation for tumor incidence and growth and then were sacrificed Tumor volume was measured using the formula Tumor volume $=1 / 2\left(\right.$ length $\times$ width $\left.^{2}\right) / 2$ as previously described $[2,7]$.

\section{Statistical analysis}

Statistical analyses were performed using Graphpad Prism software (San Diego, CA) for t-test analysis, where comparisons between two groups were involved, and analysis of variance were, more groups are present to determine statistical significance, and differences were considered statistically significant at $P<0.05$.

\section{Results}

MASTL is markedly upregulated in colorectal cancer

To characterize the potential role of MASTL in colon carcinogenesis, we first assessed its expression in a high through-put transcriptome analysis of a large patient cohort (combined Moffitt Cancer Center/Vanderbilt Medical Center expression array data set using 250 CRC patient tumors and 10 normal adjacent tissue samples as described previously [demographics; [7]]). We found robust stage-specific up-regulation of MASTL transcript levels compared to normal adjacent mucosal specimens (Fig. 1a; $P<0.001)$. We found a similar significant increase in MASTL expression in all stages of colon cancer compared to normal samples, analyzing the TCGA database (Fig. 1b).

To examine if the observed increase in MASTL mRNA expression was translationally relevant, we determined MASTL expression in a panel of colorectal cancer cell lines, animal models of colon cancer as well as a commercial colon cancer tissue array [immunohistochemical (IHC) analysis; 50 samples]. We found that immunoblotting using lysates from confluence matched cell lines indeed demonstrated a similar increase in MASTL expression in colon cancer cells versus non- transformed intestinal epithelial cells (IEC-6) (Additional file 1: Figure S1A). IHC analysis also revealed marked increase in MASTL expression in CRC tissue samples (compared to normal colon; Fig. 1c). To corroborate these findings, we further determined MASTL expression in colon tumor samples from a murine model of sporadic colon cancer (CRC; the APCmin mice) and colitis- associated cancer (CAC; AOM/DSS induced mouse model). A significant increase in MASTL expression was observed in tumors from both colon cancer models (Fig. 1d). These findings validated a positive association between MASTL expression and colon cancer progression.

We further determined whether high MASTL expression could also identify high-risk colon cancer patients. Overall survival estimates based on MASTL expression were determined in the CRC patient database as described previously [7]. We used a median cut-off for MASTL expression (higher-than-median = high MASTL expression; lower-than-median = low MASTL expression). We noted a significant association of better overall survival for patients with lower-than-median MASTL expression (Fig. 1e, $p=0.03$ ) while patients exhibiting high MASTL expression had worse overall survival. We found a similar trend using disease-specific survival as an outcome measure (Fig. 1f, $p=0.05$ ). Our additional analysis, wherein we divided patients into four quartiles based on MASTL expression values and performed Kaplan-Meier analysis, revealed a similar trend 
a

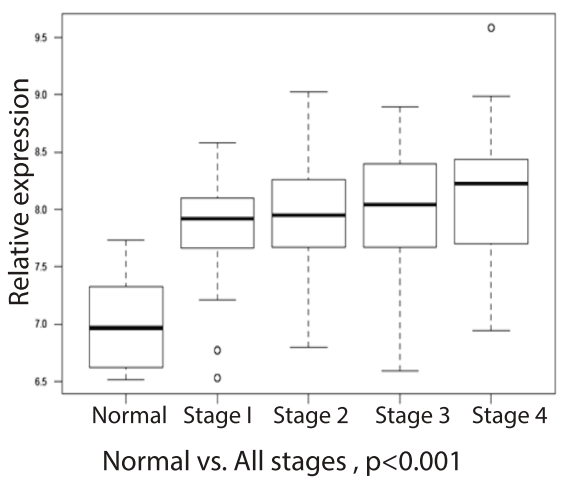

C

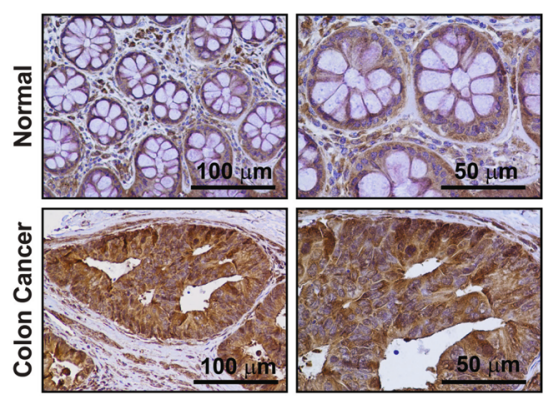

b

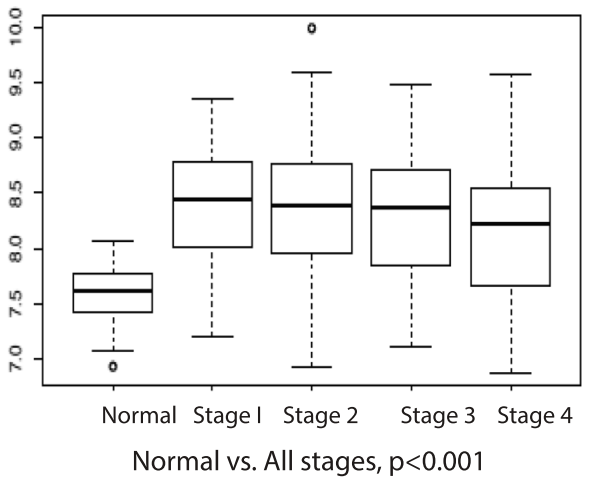

d
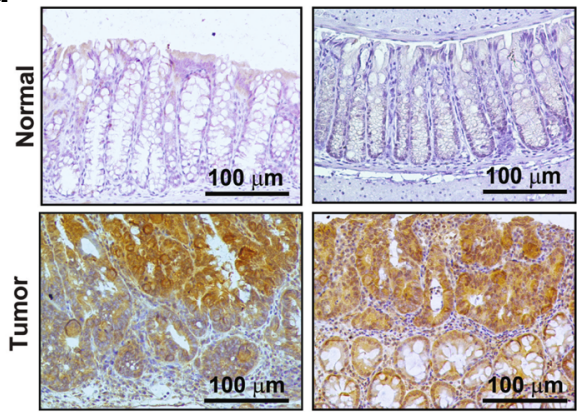

APCmin

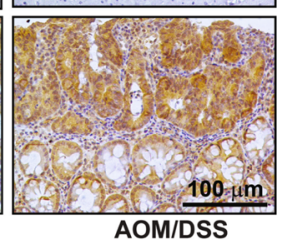

Disease-specific survival

f

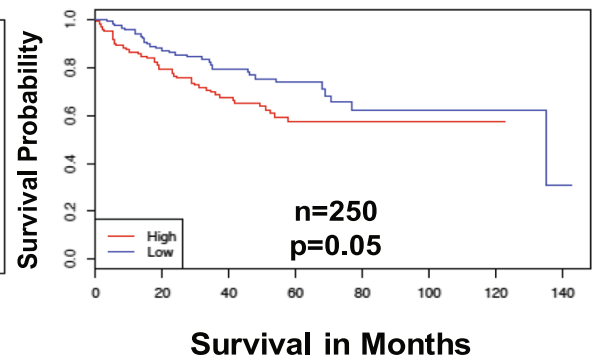

Fig. 1 MASTL expression is upregulated in colon cancer. Patients were evaluated by tumor stage and expression levels were compared to expression levels of normal adjacent samples. a 250 patients were analyzed from the VMC/MCC data set. Wilcoxon rank sum test was used to test for significance between each stage and normal $(P<0.001)$. b 315 patients were analyzed from the TCGA database. Kruskal- Wallis rank sum test was used to test for significance between each stage and normal $(P<0.001)$. Immunohistochemical analysis of $(\mathbf{c})$ normal and colon cancer patients \& $(\mathbf{d})$ AOM/DSS and $A P C^{\text {min }}$ mice tumors for MASTL expression. e \& $\mathbf{f}$ Comparison of overall survival and disease-specific survival in correlation with MASTL expression. Patients with high expression were defined as having greater than median expression of MASTL and were compared to the low expression group (less than the median expression value). Kaplan-Meier analysis was performed, comparing patients with high MASTL expression (red line) to low MASTL expression (blue line). Higher expression of MASTL correlated with significantly worse overall survival $(P=0.03, n=250)(A)$ and a trend toward worse disease-specific survival $(P=0.05, n=250)$

(Additional file 1: Figure S1B). These data rendered strong evidence that MASTL can serve as a prognostic biomarker for latent disease aggressiveness among colorectal cancer patients.

Inhibiting MASTL expression in colon cancer cells inhibits neoplastic growth and invasive mobility

In further studies, to identify the causal significance of MASTL expression in CRC progression and the specific tumorigenic trait that is affected by MASTL expression, we evaluated tumorigenic and invasive properties of HCT116 and SW620 cells in response to inhibition of MASTL expression. Selection of cell lines for these studies was based on known tumorigenic/metastatic potential and high MASTL expression. Anti-human MASTL shRNA was expressed in these cells and silencing efficiency was confirmed by qRT-PCR, immunoblotting and immunofluorescence analyses (Fig. 2a (i\&ii), Additional file 1: 
Figure S2). HCT116MKD and SW620MKD cells (with inhibition of MASTL expression) were analyzed using the anchorage-independent growth and matrigel-coated transwell-based invasion assays. Inhibition of MASTL expression significantly inhibited cell invasion $(P<0.05)$ and the ability of these cells to form colonies in soft agar by $60-80 \%(P<0.05)$ \{Fig. $2 \mathrm{~b}$ (i\&ii) and Additional file 1 : Figure S3\}. These data supported a necessary role of MASTL in promoting the oncogenic and metastatic properties of colon cancer cells.

MASTL knockdown arrests cell cycle at G2/M and induces apoptosis in colon cancer cells

To ascertain specific cellular function affected by MASTL expression for these observed changes, we performed cell cycle analysis using HCT116MKD and SW620MKD and respective control cells.

Confluent cell monolayer was serum-starved for $72 \mathrm{~h}$ to achieve cell synchronization.

Thereafter, cells were treated with RO3306 $(10 \mu \mathrm{M})$, widely used to arrest cell cycle at G2/M interphase [8] for $16 \mathrm{~h}$. Cells were released into the cell cycle by exposing them to fresh medium for $1 \mathrm{~h}$. At this time, cells were collected for cell cycle analysis. As shown in Fig. 3, control cells progressed in the cell cycle to the G0/G1 phase. MASTL knockdown cells, however were unable to overcome the G2/M block by RO3306 so as to enter mitosis. As expected, beyond this, the percentage of cells in $\mathrm{G} 2 / \mathrm{M}$ was 3-5 fold higher in HCT116MKD cells (Fig. 3a, $p<0.05$ ) and SW620MKD cells (Fig. 3b, $p<0.05$ ) compared to respective control cells.

$\mathrm{G} 2 / \mathrm{M}$ arrest can lead to apoptosis in various cancer cell lines, including colon cancer cells [9-11]. We thus next determined whether MASTL knockdown modulated proliferation or apoptosis by inhibiting the cell cycle at the G2/M interphase. To determine potential changes in cell- proliferation, MASTL knockdown and control cells were subjected to Edu-incorporation assay where it was observed that inhibiting MASTL expression significantly inhibited proliferative capacity of HCT116MKD and SW620MKD cells (Fig. 4a (i\&ii)). To determine potential changes in apoptosis, cells were subjected to annexin- $\mathrm{V}$ and caspase activity assays. The annexin- $\mathrm{V}$ analysis revealed significant increases in both

\section{a}

(i)
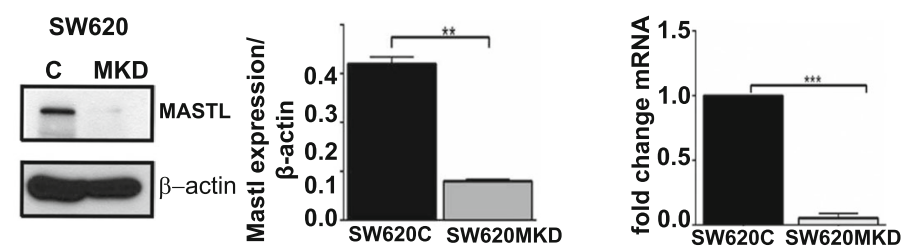

(ii)
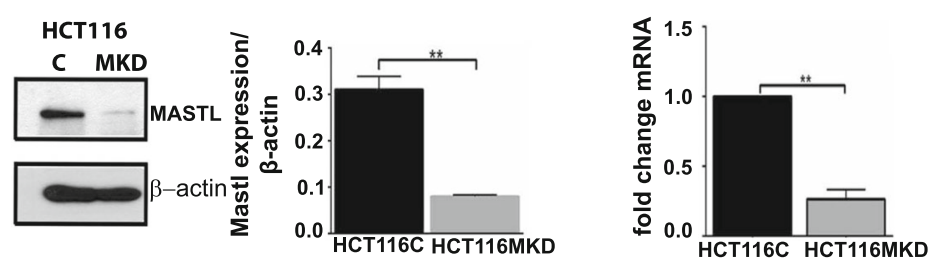

b

(i)
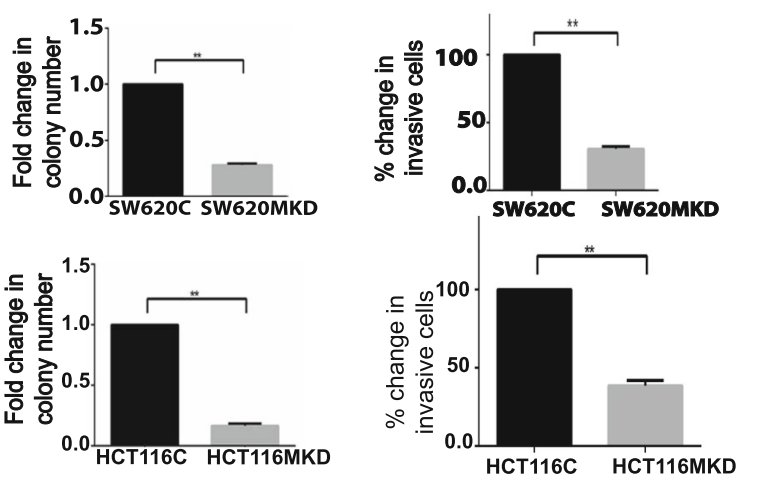

Fig. 2 MASTL knockdown results in altered functional characteristics in colon cancer cell lines in vitro. a (i) MASTL knockdown in SW620 cells was confirmed by Western blot and qRT-PCR analysis. (ii) MASTL knockdown in HCT116 cells was confirmed by Western blot and qRT-PCR analysis. $\mathbf{b}$ Tumorigenic and invasive potential was determined by ability to form colonies in soft agar assay and invasion in (i) SW620C and SW620 MKD cells (ii) HCT116C and HCT116 ${ }^{\mathrm{MKD}}$ cells. For graphs, data represent mean $\pm \mathrm{SD}$; ${ }^{*}, P<0.001$ 

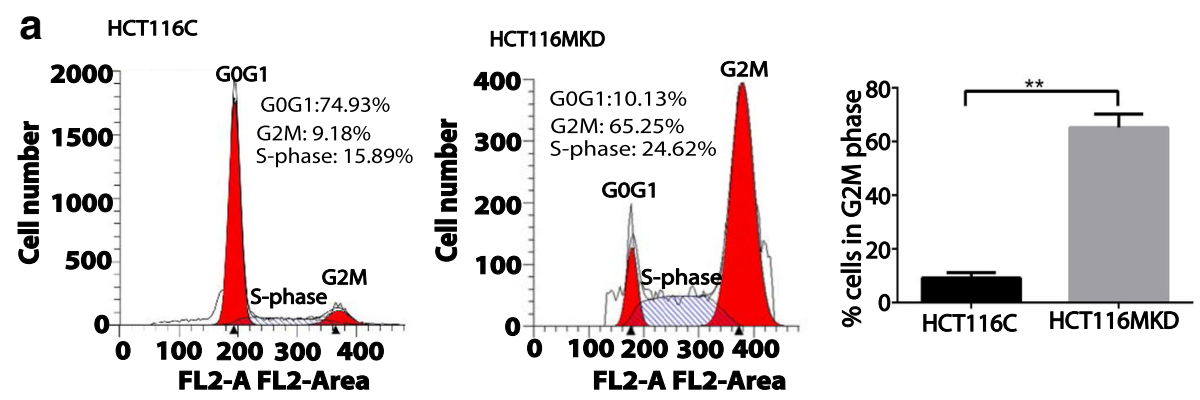

b
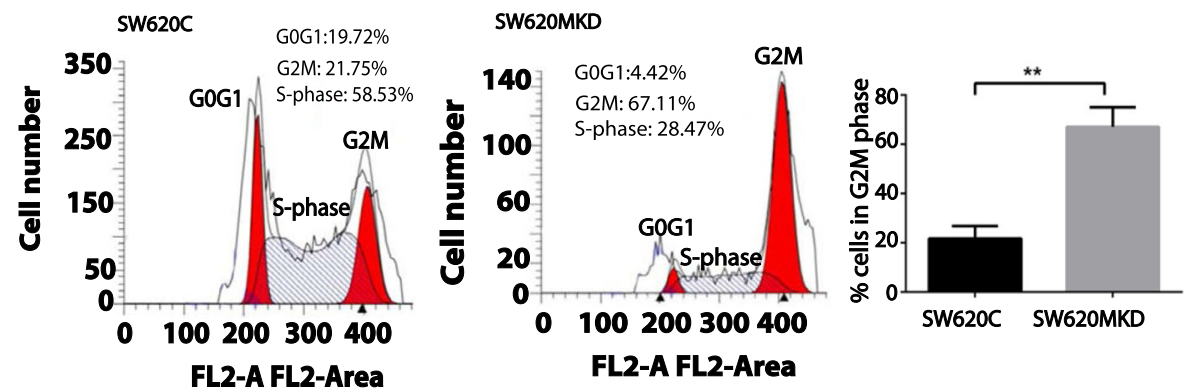

Fig. 3 Cell are arrested in G2M phase as a result of MASTL knockdown in colon cancer. Control and MASTL knockdown cells were synchronized in serum free conditions for $72 \mathrm{~h}$ after which are treated with RO3306 for $16 \mathrm{~h}$ and then grown for one hour in fresh media. Cells were fixed immediately and cell cycle analysis was carried out via FACS. RO3306 is a selective ATP-competitive inhibitor of CDK1 that reversibly arrests proliferating human cells at the G2/M phase border, and the arrested cells enter mitosis rapidly after release from the G2 block [8] (a) HCT116 MASTL knockdown cells were unable to overcome the G2M block as compared to control cells (b) Similarly, the SW620 MASTL knockdown cells were also significantly arrested in G2M phase. For graphs, data represent mean \pm SD; ${ }^{*}, P<0.01$

early and late apoptosis in HCT116MKD (Fig. 4b(i)) and SW620MKD cells (Fig. 4c(i)) compared to control cells $(p<0.05)$. Caspase $3 / 7$ activity was also increased $-3-4$ fold in these cells, suggesting a necessary role for MASTL in the regulation of processes determining cell multiplication and death (Fig. 4b (ii), C(ii)).

MASTL regulates the anti-apoptotic proteins, Survivin and $\mathrm{Bcl}-\mathrm{xL}$, by modulating Wnt/ $\beta$ - catenin signaling to promote colon tumorigenesis

To further examine the precise molecular mechanisms modified by genetic silencing of MASTL expression to induce aggressive phenotype, we performed an analysis of the global changes in protein expression, especially for proteins implicated in promoting oncogenesis, using a well-controlled and commercially available oncogenic array (Additional file 1: Figure S3). We focused on proteins which were reproducibly altered in both colon cancer cells (HCT116 ${ }^{\mathrm{MKD}}$ and SW620 ${ }^{\mathrm{MKD}}$ ). As shown in Additional file 1: Figure S4, we found consistent and significant alterations in the expression of Survivin and Bcl-xL, key proteins of anti-apoptotic pathways and upregulated in cancer cells [12-15], in MASTL-silenced cells versus control cells. We further confirmed significant downregulation of Bcl-xL and Survivin expressions using immunoblotting in MASTL-inhibited colon cancer cells compared to respective controls (Fig. 5a, b). Of note, Survivin is one of the downstream target genes of the $\mathrm{Wnt} / \beta$-catenin signaling pathway $[15,16]$. A critical significance of hyper-activated $\mathrm{Wnt} / \beta$-catenin signaling in colon tumorigenesis is well established [16, 17]. Moreover, $\beta$-catenin expression is elevated during the G2/M interphase of the cell-cycle progression $[18,19]$. We therefore reasoned that there might be a causal correlation between MASTL and Wnt/ $\beta$-catenin signaling in promoting colon carcinogenesis through modulating Survivin and/or Bcl-xL expressions. Therefore, we further determined the effects of MASTL-knockdown upon $\beta$-catenin expression, cellular localization, and transcriptional activity (Fig. 5c (i\&ii)). We found that knockdown of MASTL also resulted in sharp decreases in $\beta$-catenin expression, as well as expression of c-Myc, a Wnt $/ \beta$-catenin signaling target gene. Further determinations demonstrated marked decreases in the nuclear accumulation of $\beta$ - catenin and transcriptional activity, as measured by the TOP-Flash reporter activity, in MASTL inhibited colon cancer cells. In contrast, forced overexpression of full-length MASTL cDNA in colon cancer cells induced sharp increases in the expression of these proteins (Additional file 1: Figure S5). To see if similar correlation between these proteins existed in CRC patient samples, we interrogated expression levels 


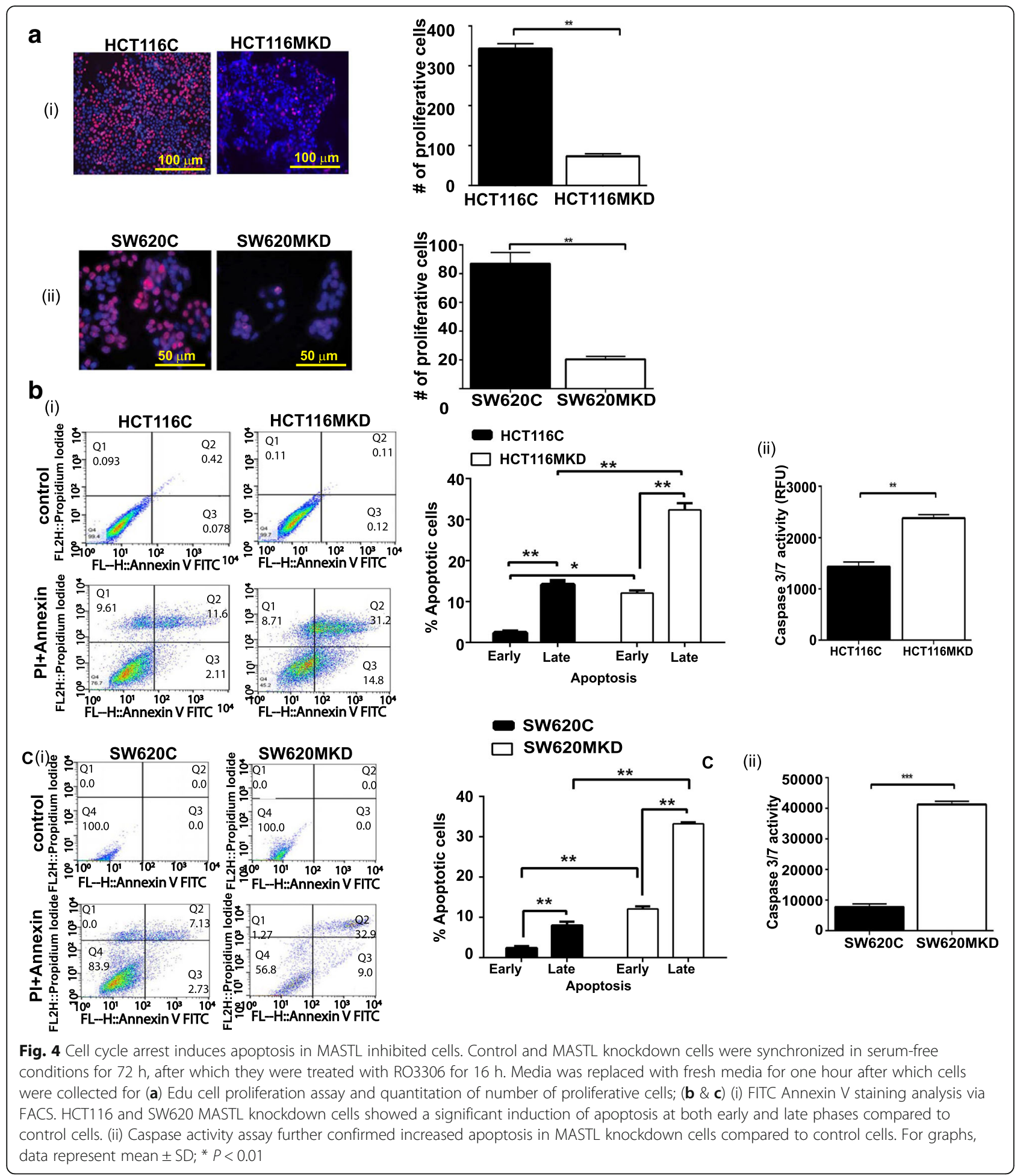

of the c-Myc, Bcl-xL and MASTL in the 260-patient CRC database used to determine MASTL expression in CRC. It was quite encouraging that levels of c-Myc and Bcl-xL (BCL2L1) expression associated with MASTL in a similar fashion in patient samples as noted in vitro (Additional file 1: Figure S6).
Of importance, glycogen synthase kinase 3 (GSK3), in complex with Axin and adenomatous polyposis coli (APC), phosphorylates $\beta$-catenin at Thr41, Ser37, and Ser33. Phosphorylated $\beta$-catenin is specifically recognized by $\beta$ - $\operatorname{TrCP}$, a subunit of the $\mathrm{SCF}^{\beta-\operatorname{TrCP}}$ E3 ubiquitin ligase complex. The $\mathrm{SCF}^{\beta-\operatorname{TrCP}}$ ubiquitin ligase poly-ubiquitinates $\beta$-catenin, 


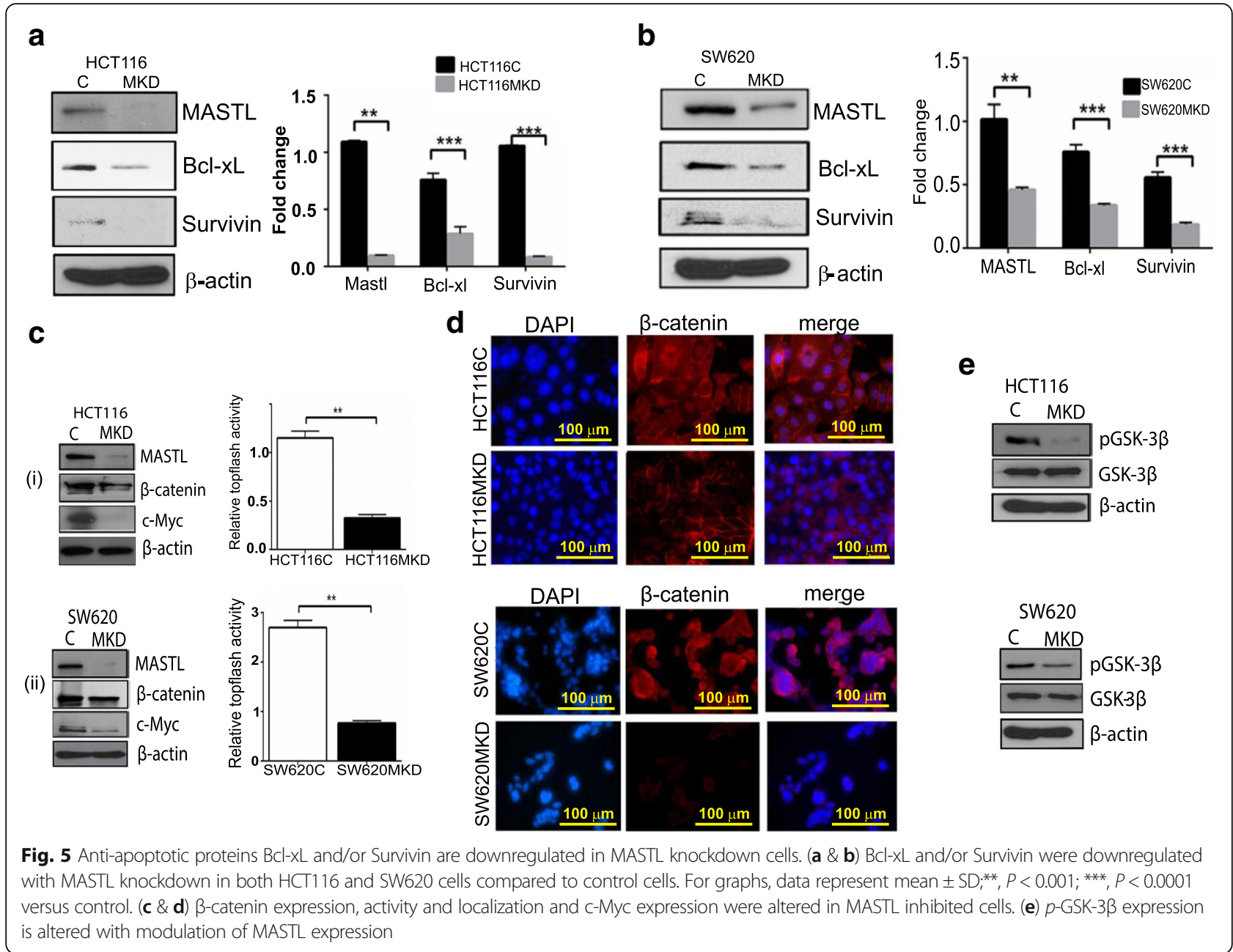

leading to $\beta$-catenin degradation via the proteosome pathway [20].

In contrast, phosphorylated and/or inactive GSK-3 $\beta$ promotes cellular accumulation and nuclear translocation of $\beta$-catenin, and initiation of the T-cell factor (Tcf)-dependent transcription. In agreement with this, GSK-3 $\beta$ phosphorylation (S9, inactive form) was seen to be markedly reduced in MASTL knockdown cells, resulting in active GSK-3 $\beta$ to induce $\beta$-catenin degradation (Fig. 5d). Further analysis showed no significant change in $\beta$-catenin mRNA expression, well in accordance with potential post-transcriptional regulation (data not shown).

\section{Inhibiting MASTL expression inhibits xenograft tumor formation by colon cancer cells in vivo}

To determine if inhibiting MASTL expression can similarly modulate colon tumorigenesis in vivo, we performed a subcutaneous xenograft tumor assay using HCT116MKD and respective control cells in athymic nude mice $(n=6 /$ group). The same mice received control and MASTL knockdown cells on opposite flanks. In line with previous reports [7], mice receiving HCT116C cells demonstrated tumor development as early as two weeks post-injection of cancer cells, and average tumor volume was $1068 \pm$ $161.2 \mathrm{~mm} 3$ at 4-weeks post-injection. By contrast, tumors resulting from injection of HCT116MKD cells were significantly smaller, with average volumes of $309 \pm 50.6 \mathrm{~mm} 3$ after the same period of growth (Fig. 6a, c). Tumor weight followed a similar pattern and was lower $(P<0.05)$ in mice injected with MASTL-inhibited cells compared to those injected with control cells (Fig. 6b). Resulting tumors were then evaluated for expression of MASTL, $\beta$-catenin, Survivin, and Bcl-xL expression. Also effects of MASTL inhibition on cell proliferation, and apoptosis in tumors were determined (Fig. 6d, e). Similar to in vitro findings, MASTL inhibition reduced expression of $\beta$-catenin, Survivin and Bcl-xL expression in tumors resulting from HCT116MKD cells. Further, an increased rate of apoptosis, as determined by cleaved PARP 


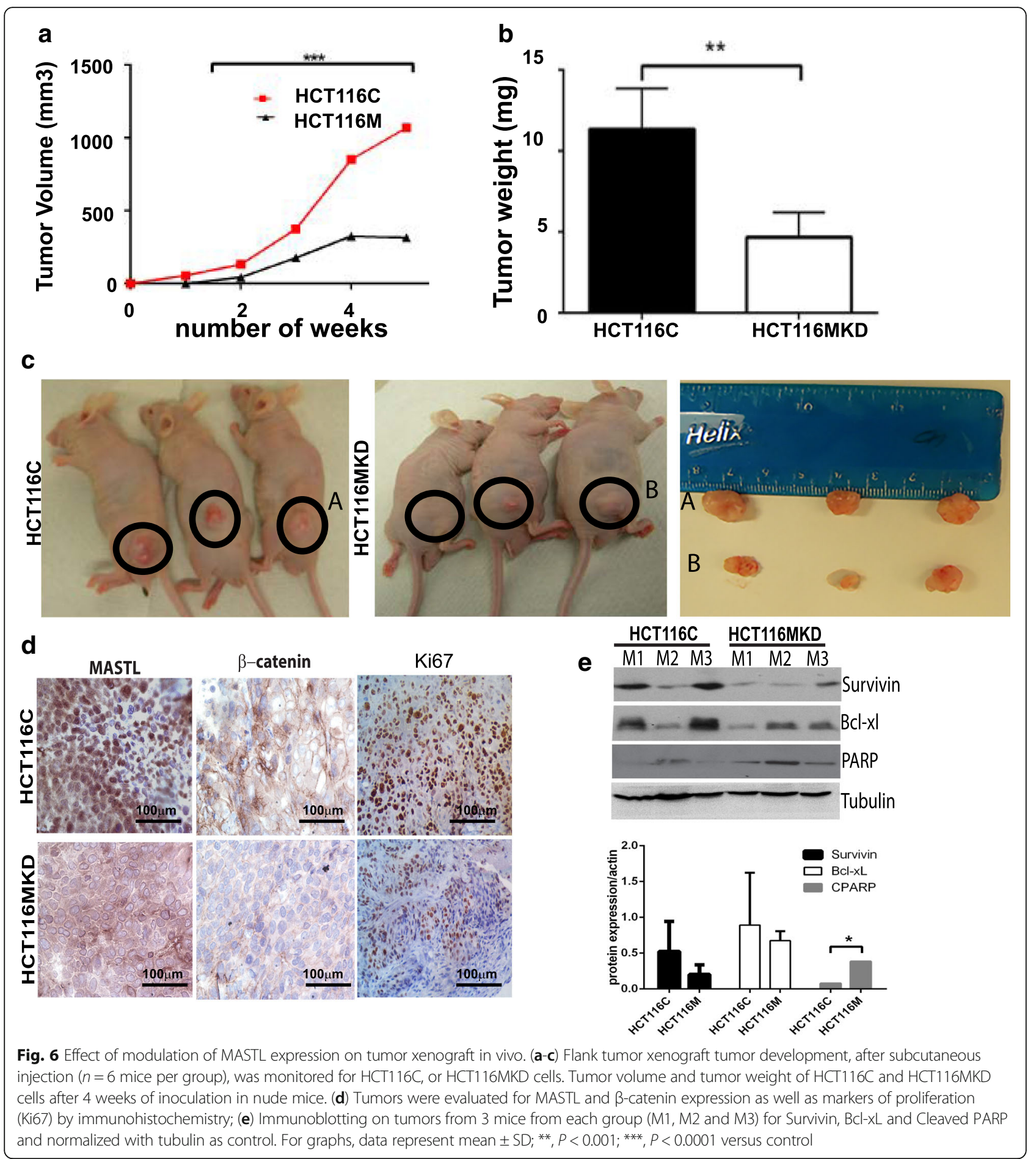

expression, while decreased proliferation as determined by Ki67 immunoreactivity in tumors resulting from HCT116MKD was observed. This suggests that inhibiting MASTL expression restores a cell death program and inhibits proliferation. These data from xenograft tumor assays provide further support for the role of MASTL in tumorigenesis in CRC.
Forced expression of genetically stabilized $\beta$-catenin rescues cellular apoptosis induced by inhibiting MASTL expression

Encouraged by these findings, we asked whether effects on apoptosis mediated by MASTL can be ameliorated by simply upregulation of $\beta$-catenin expression. We overexpressed a mutant $\beta$-catenin (S33Y) construct (which resists 
proteosomal degradation and thus is highly stable) in both HCT116MKD and SW620MKD cells. Overexpression of $\beta$-catenin and its expected effect on promoting Wnt $/ \beta$-catenin signaling was confirmed by immunoblotting and TOPFlash promoter reporter (Fig. 7a, b). Overexpression of activated $\beta$-catenin in MASTL-inhibited cells inhibited apoptosis $(40-50 \%)$ and levels were similar to controls cells (Fig. 7c) suggesting effects of MASTL on cell viability are mediated by modulating $\beta$-catenin expression and activity.

\section{MASTL expression induces resistance to anti-colon cancer} therapy

In head and neck cancer, up-regulation of MASTL expression promotes cancer progression and tumor recurrence after initial cancer therapy [2]. In the light of our data that MASTL expression is directly proportional to the CRC progression, we reasoned that MASTL expression may similarly promote resistance against conventional anti-CRC therapy using 5-FU. To determine the validity of this supposition, control, HCT $116^{\mathrm{MKD}}$, and SW620 ${ }^{\mathrm{MKD}}$ cells were subjected to $5 \mathrm{FU}$-treatment (10 or $20 \mu \mathrm{M})$. Immunoblotting using cell lysate prepared from these samples demonstrated significant increases in MASTL expression, along with Survivin and Bcl-xL expressions, suggesting a potential role for these molecules in chemotherapeutic resistance (Fig. 8a). Further analysis showed that the increase in Survivin and $\mathrm{Bcl}-\mathrm{xL}$ expressions in 5FU-treated control cells was significantly reduced in MASTL-inhibited cells even in the presence of $5 \mathrm{FU}$ probably making these cells more sensitive to chemotherapy (Fig. 8a). Similar results were obtained in SW620 cells (Additional file 1: Figure S7).

We then hypothesized that inhibition of MASTL would reduce survival signaling downstream of MASTL and induce chemosensitivity. We again subjected control
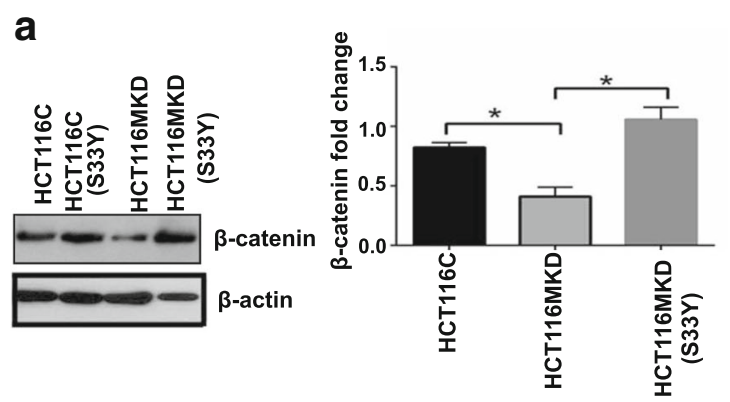

b
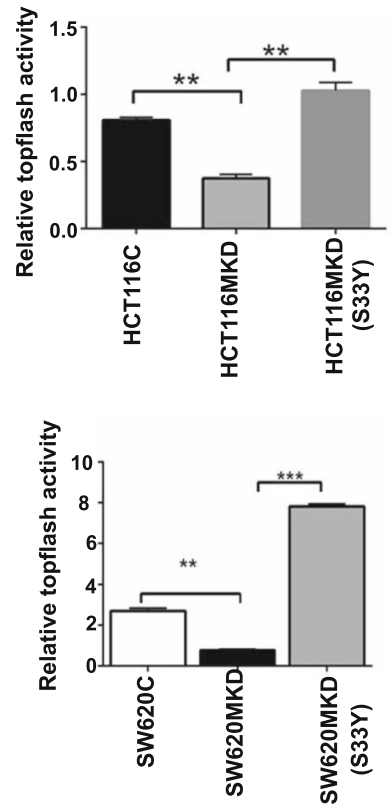

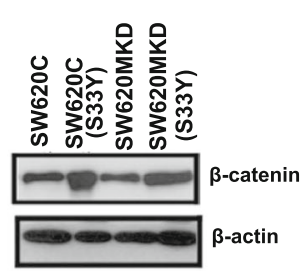

C

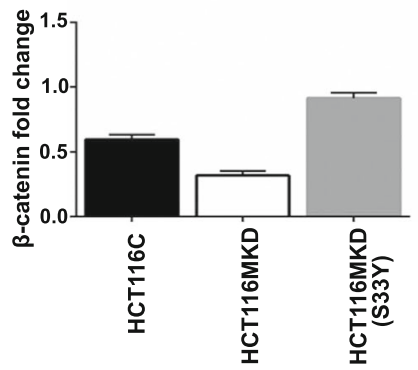

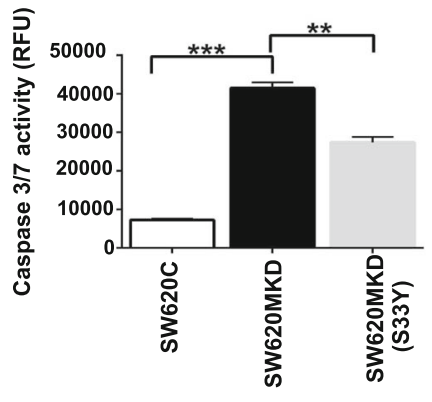

Fig. 7 Overexpression of $\beta$-catenin-S33Y mutant rescues MASTL knockdown cells from apoptosis. $\beta$-catenin-S33Y mutant was transiently overexpressed (48 h) in MASTL knockdown cells and overexpression of activated $\beta$-catenin was confirmed by immunoblotting and topflash reporter assay in HCT116 (a) and SW620 (b) cells. c Caspase-3/7 activity as measured by luminescence in HCT116 ${ }^{\text {MKD }}$ and SW620 MKD cells as compared to control cells and modulation due to overexpression of activated form of $\beta$-catenin in these cells 


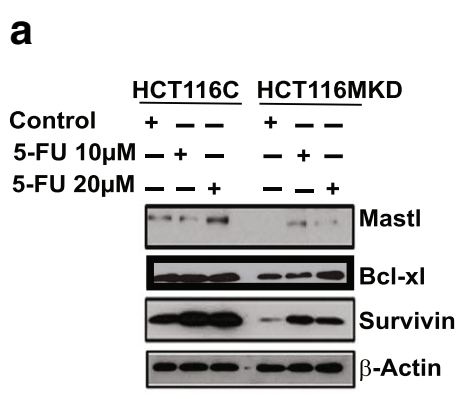

C

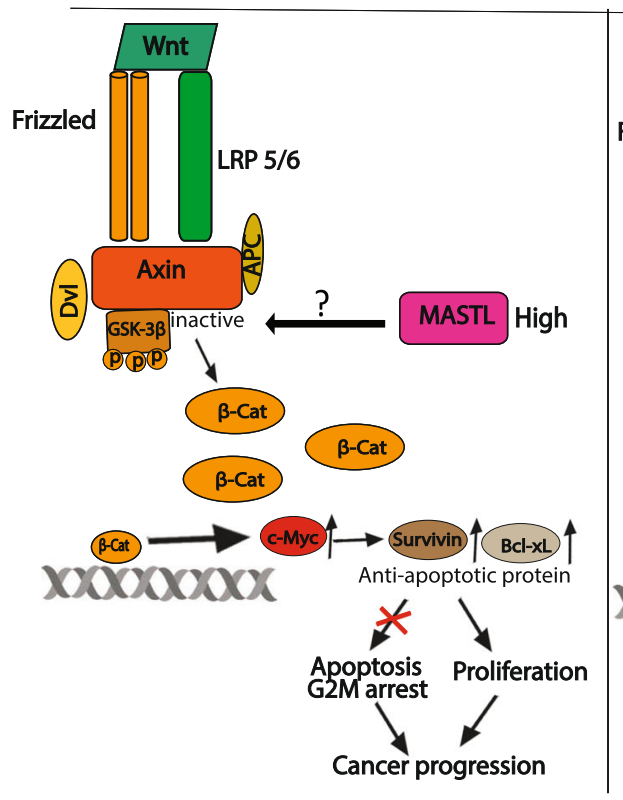

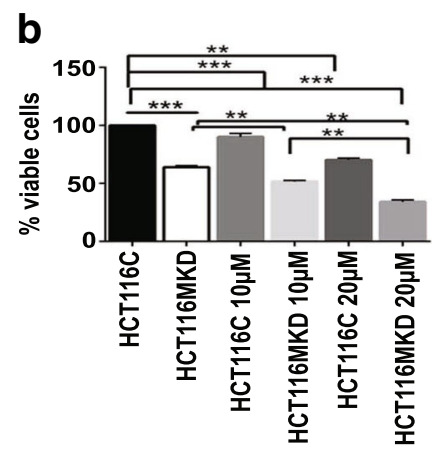

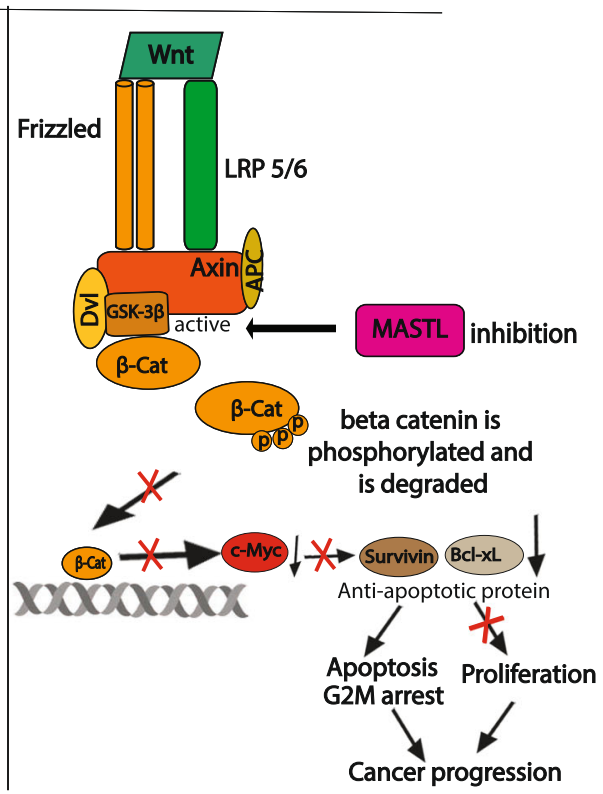

Fig. 8 MASTL imparts chemoresistance to 5-FU in colon cancer cell lines. (a) HCT116C and HCT116 ${ }^{\text {MKD }}$ cells were treated with 10 and $20 \mu \mathrm{M}$ of 5-FU. Western blot analysis demonstrated induction of Survivin and Bcl-xL in control cells. However, inhibition of MASTL inhibited these protein expression even in presence of 5-FU. (b) MTT assay in HCT116C and HCT116 ${ }^{\mathrm{MKD}}$ cells showed significant reduction in viable cells as compared to control treated cells. For graphs, data represent mean $\pm \mathrm{SD} ;{ }^{* *}, P<0.001 ; *^{* *}, P<0.0001$ versus control. (c) Model depicting the role of MASTL in regulation of colon cancer progression. When MASTL expression is increased it phosphorylates GSK-3 $\beta$ and inactivates it, thereby $\beta$-catenin is not phosphorylated and degraded. The $\beta$-catenin then is translocated into nucleus leading to active transcription of its target genes c-Myc, Survivin and $\mathrm{BCl}-\mathrm{xL}$. These cells escape G2M arrest and apoptosis leading to cancer progression. Conversely, in MASTL inhibited cells, GSK-3 $\beta$ is active which then phosphorylates and degrades $\beta$-catenin thus preventing its translocation to nucleus and activation of target genes

and MASTL knockdown cells to 5FU-treatment (both cell lines being highly metastatic and chemoresistant). Treatment with 5FU could only induce $25-30 \%$ cell death in control HCT116 cells. However, 5- FU treatment was significantly more effective in the same cells in the absence of MASTL expression $\left(\mathrm{HCT} 116^{\mathrm{MKD}}\right)$, with cell survival significantly reduced $(60-70 \%)$ (Fig. 8b, $P<0.001)$. Similar results were observed in SW620C and SW620 ${ }^{\mathrm{MKD}}$ cells. These observations further support a key role for MASTL in resistance to chemotherapeutic agents for colorectal cancer. A postulated model depicting MASTL-dependent regulation of $\beta$-catenin to regulate cmyc/Survivin/Bcl-xL expression, associated signaling and cellular functions is presented in Fig. 8c.

\section{Discussion}

The central role of the uncontrolled and/or dysregulated cell division in promoting malignant growth means that targeting the cyclin-dependent kinases (Cdks), key regulators of the cell cycle, is the most desired line of anti-cancer drug development, by university researchers and pharmaceutical companies. Several Cdks, including Polo-like and Aurora kinase, have recently emerged as important regulators of the cell-cycle progression with a causal association to cancer progression [21, 22]. However, attempts to employ these have been hindered primarily by significant side effects associated with killing of the normal cell division that is essential for maintaining function of several organs. In current studies, we 
identify MASTL as a therapy target in colon tumorigenesis that appears to be highly upregulated in cancer cells, and thus promises minimal toxicity. Our data that this protein not only shows stage-specific increases in CRC patients but negatively associates to patient survival further support its use as a promising anti-cancer therapeutic target. Our additional data that depletion of MASTL expression significantly suppresses chemoresistance in CRC cells against conventional anti-CRC therapy agent 5-FU further highlights its efficacy in effective clinical management of the disease.

Of importance, the MASTL protein has been shown to be critical for mitosis [23]. The MASTL/Greatwall kinase is activated during the G2/M transition due to phosphorylation by cyclin- B-Cdk1, followed by autophosphorylation of the C-terminal activating site. Activation of this kinase, in turn, promotes inhibition of PP2A-B55 through phosphorylation of its substrates, Arpp19 and ENSA [1, 24-26]. This inhibition results in stable phosphorylation of cyclin-B-Cdk1 substrates and mitotic entry. Once mitosis is complete, the cell must exit mitosis, and to do this, the prevailing phosphorylation(s) has to be removed. Removal is suggested to be accomplished by reversing the inhibitory effect of MASTL on phosphatases by PP1 [27]. Our data are well aligned with the understanding of the regulatory role for MASTL in cell cycle regulation in colon cancer cells, given that inhibiting MASTL was sufficient to inhibit cell cycle progression and mitosis. Furthermore, MASTL depleted colon cancer cells demonstrated cell cycle arrest at the G2/M phase and significant increase in apoptosis. The novelty of our studies is in our observation that MASTL regulates $\mathrm{Wnt}-/ \beta$-catenin signaling hyperactivation, critical regulator of colon tumorigenesis, to promote colon carcinogenesis. Mechanistically, based on our data, we postulate that MASTL inhibition leads to activation of Gsk3 $\beta$, which in turn induces phosphorylation and thus degradation of the oncogenic $\beta$-catenin expression. This $\beta$-catenin downregulation leads to decrease in cellular content of the c-Myc, Survivin and Bcl-xL, which ultimately leads to apoptotic cell death. Previous studies have shown c-Myc network is required for the majority of Wnt target gene activation following Apc loss within intestinal epithelium [28]. Whether MASTL expression alone is sufficient for this function or its phosphorylation or other activity is also involved remains to be determined.

The role of MASTL in promoting colon cancer is supported by our findings that its expression is markedly increased in colon cancer cells, in transcriptome and protein expression analyses of a large CRC patient cohort, in the cancer genomic atlas (TCGA) database, and in colon tumors that result from mouse model of sporadic or inflammation-induced colon cancer. These findings get strong support from similar upregulation of MASTL through Akt pathway in a recent study using another CRC patient cohort [29]. Moreover, our data from colon cancer cells or xenograft tumor growth assays demonstrate that increased MASTL expression can serve as an independent predictor of poor clinical outcome in colon cancer. Most notably, our studies suggest that normal colonocytes either don't express MASTL or express it at negligible levels. By contrast, cancer cells demonstrate robust MASTL expression, especially by cells that were highly tumoroigenic and metastatic, including HCT116 and SW620 cells. Thus, inhibition of MASTL expression in these cells negatively affected their ability to grow in soft agar, invade through the matrix, and to induce tumor growth in vivo. Further, inhibition of MASTL expression arrested cell cycle progression in colon cancer cells at the G2/M interphase, and induced apoptosis. Apoptosis, the outcome of a series of regulated cellular events often suppressed in tumors, can induce a variety of genes involved in cell-cycle inhibition by targeting the G2/M checkpoint [30, 31].

Upregulation of $\beta$-catenin signaling by its deregulation or mutational activation has been shown to be present in various human cancer types and is associated with cancer progression and metastasis [32-34]. Additionally, it has been observed that levels of $\beta$-catenin increases in the $S$ phase, reaching maximum accumulation at late G2/M and further decreases by the next G1 phase [18]. Yet another study demonstrated a plausible mechanism of G2/M cell-cycle arrest and abrogation of the Wnt/ $\beta$-catenin pathway, using withanolide-D (witha-D), a steroidal lactone in pancreatic adenocarcinoma cells [19]. $\beta$-catenin is a critical regulatory molecule of the canonical Wnt-signaling pathway and plays an important role in regulating diverse cellular processes, including cell proliferation, survival, migration, invasion, polarity, differentiation, development, and stem cell self-renewal [35]. c-Myc is a direct target of $\mathrm{Wnt} / \beta$-catenin-signaling and has been attributed to having roles in chromosomal rearrangement and remodeling through telomeres [36] as well as in G2/M arrest following DNA damage, leading to an inappropriate entry of damaged chromosomes into mitosis [37]. Of interest, c-Myc is aberrantly expressed in $60-80 \%$ in CRC and universally implicated in promoting colorectal tumorigenesis [38, 39], including colitis-associated colon adenocarcinomas [40-44] and c-Myc expression confers resistance against 5FU [45-48]. Overexpression of c-Myc is responsible for altering G2/M arrest in aberrant cells, which leads to the entry of damaged chromosomes into mitosis [37], similar to MASTL overexpression. Our findings strongly indicate that MASTL regulate $\beta$-catenin expression and cellular localization to modulate its transcription activity and c-Myc expression to regulate colon cancer. 
Inactivation of GSK-3 $\beta$, a primary kinase in the $\beta$-catenin multi-protein destruction complex, is frequently found in human cancers. Of note, Akt/GSK-3 $\beta$ phosphorylates $\beta$-catenin on conserved serine and threonine residues in its amino terminus to initiate its ubiquitination and subsequent proteasomal degradation $[33,49,50]$. Inactivation of GSK-3 $\beta$ by phosphorylation reduces ubiquitination of $\beta$-catenin, resulting in its nuclear accumulation and increased transcriptional activity. In line with this, we detected a decrease in the phosphorylation level of GSK-3 $\beta$ (inactive) that resulted degradation and significant downregulation of total $\beta$-catenin protein following inhibition of MASTL expression in HCT116 and SW620 cells. Our results suggest that the MASTL/GSK-3 $\beta$ axis, regulate $\beta$-catenin expression. Recent studies using Boolean modeling have also identified Greatwall/MASTL as an important regulator of the Aurora kinase (AURKA) network in neuroblastoma. AURKA overexpression has been shown to mediate pro-tumorigenic functions in addition to mitosis, and drugs aimed at inhibiting its expression to improve anti-cancer therapy are currently under clinical trials [51-53]. Previous studies also demonstrated that AURKA directly binds with GSK-3 $\beta$, and phosphorylates at Ser9. Whether MASTL associates directly with GSK-3 $\beta$ or indirectly through AURKA, and whether Akt plays a role in this regulation, remains to be determined. GSK-3 $\beta$ has been previously identified as key downstream target of the PI3-kinase/ AKT survival signaling pathway [54-56]. It is therefore possible that MASTL regulates GSK-3 $\beta$ phosphorylation through direct interaction, and/or through a MASTL/AKT axis-dependent mechanism.

Another important observation in our studies is that MASTL inhibition renders cells more sensitive to apoptosis that has been induced by 5FU-treatment. Since many anti-cancer drugs result in DNA cross-linking damage, these findings are of high clinical relevance. Our findings suggest that MASTL overexpression can contribute to anti-cancer drug resistance in colon cancer cells by up-regulating Survivin and Bcl-xL expressions. A similar role of MASTL in tumor resistance has been demonstrated in head and neck cancer patients. Of note, MASTL knockdown in recurrent tumor cells re-sensitized their response to cancer therapy in vitro and in vivo, and this was similar to our findings in colon cancer cells [2]. MASTL targeting specifically and importantly potentiated non-small cell lung cancer cells to cell death in chemotherapy, while sparing normal cells [1], revealing that MASTL upregulation helps promote cancer progression and tumor recurrence after initial cancer therapy, and strongly supporting MASTL as a promising target of increased therapeutic efficacy of anti-cancer therapies, including anti-CRC therapy.

We show that overexpression of MASTL correlates with colon cancer recurrence and progression. Thus, the inhibition by MASTL of drug-induced cell death may not only account for failure of standard chemotherapy, but may also help explain why MASTL overexpression contributes to the malignant phenotype of colon cancer. The data presented in this study strongly supports a promotive role for MASTL in colon cancer, and the potential association of MASTL with anti-cancer therapy efficacy. Future detailed analyses of a large patient cohort and different publicly available datasets will help confirm the putative role of this protein in prognostic prediction for latent aggressiveness of CRC and resistance to therapy.

\section{Conclusion}

The present study depicts a novel role for MASTL in regulating $\mathrm{Wnt} / \beta$-catenin signaling to modulate $\mathrm{c}-\mathrm{Myc}$ and Survivin expression in promoting colon cancer and therapy resistance. Thus understanding the novel functions of MASTL will help in the development of new colon cancer therapeutic approaches.

\section{Additional file}

\begin{abstract}
Additional file 1 Figure S1. (A) Immunoblotting for normal (IEC-6) and colon cancer cells for MASTL expression. (B) Comparison of overall survival in correlation with MASTL expression. Patients were divided into quartiles 1-4 on basis of MASTL expression values. Kaplan-Meier analysis performed, comparing patients in each quartile. Patients with higher MASTL expression have greater overall survival $(P=0.09, n=250)$. Figure S2. Inhibition of MASTL expression in SW620 and HCT116 cells. SW620 and HCT116 control and MKD cells were immunostained for MASTL and were co-localized with DAPI. Figure S3. Human Oncology array demonstrates downregulation of anti-apoptotic Survivin and BCl-xL in MASTLinhibited cells. A-15,16-BCl-xL, G21,22-Survivin. Figure S4. MASTL overexpression induces expression of $\beta$-catenin and percentage of viable cells. (A) Immunoblot analysis demonstrated induction of $\beta$-catenin, Survivin and BCl-xL in MASTL overexpressing (MOE) SW480 cells. (B) Cell viability was also increased in even in presence of 5FU in MASTL overexpressing cells as compared to control cells. Figure S5. Correlation between MASTL expression and C-Myc, and BCL2L1. (A) MYC expression is significantly upregulated with MASTL expression $(P<0.0001$, Spearman's Correlation $=$ $0.4)$. (B) BCL2L1 (BCl-xL) is significantly upregulated with MASTL expression $(P=0.05$, Spearman's correlation $=0.1)$. Figure. S6 SW620 control and MASTL knockdown cells treated with 10 and $20 \mu \mathrm{M}$ of 5-FU. (A) Western blot analysis demonstrated induction of $\beta$-catenin, Survivin and $\mathrm{BCl}-\mathrm{xL}$ in control cells. Inhibition of MASTL inhibited these protein expressions even in presence of 5FU. (B) MTT assay and (C) caspase activity assay in HCT116 and SW620 control and MASTL knockdown cells showed significant reduction in viable cells as compared to control treated cells. For graphs, data represent mean $\pm S D ;{ }^{* *}, P<0.001 ;{ }^{* * *}, P<0.0001$ versus control. (PDF 767 kb)
\end{abstract}

\section{Abbreviations}

APC: adenomatous polyposis coli (APC); CAC: Colitis associated cancer; CDK: cyclin dependent kinase; CRC: Colorectal Cancer; MASTL: Microtubule associated serine threonine like kinase

\section{Acknowledgements}

This study was supported by BX002086 (VA merit), CA216746 (NIH/NCl) and a pilot project award from Fred and Pamela Buffet Cancer Center, which is funded by a National Cancer Institute Cancer Center Support Grant under award number P30 CA036727 to P.D and DK088902 (NIH/NIDDK) and BX002761 (VA merit) A.B.S. 


\section{Funding}

This study was supported by BX002086 (VA merit), CA216746 (NIH/NCI) and a pilot project award from Fred and Pamela Buffet Cancer Center, which is funded by a National Cancer Institute Cancer Center Support Grant under award number P30 CA036727 to P.D and DK088902 (NIH/NIDDK) and BX002761 (VA merit) A.B.S. JJS is supported by the American Society of Colon and Rectal Surgeons Career Development Award, the Joel J. Roslyn Faculty Research Award, The American Society of Colon and Rectal Surgeons Limited Project Grant, the MSK Department of Surgery Junior Faculty Award and The Wasserman Colon and Rectal Cancer Fund.

\section{Availability of data and materials}

All data generated or analysed during this study are included in this published article and its additional files.

\section{Authors' contributions}

PD and SBU conceived the study and participated in the study design, performance, coordination and manuscript writing. SBU, SG, RA, BK, BS, XC, JJS carried out the assays and analysis. ABS and SB revised the manuscript. All authors reviewed and approved the final manuscript.

\section{Ethics approval and consent to participate}

All experiments were approved by the Ethics Committee of University of Nebraska Medical Center.

\section{Consent for publication}

All authors agreed on the manuscript.

\section{Competing interests}

The authors declare that they have no competing interests.

\section{Publisher's Note}

Springer Nature remains neutral with regard to jurisdictional claims in published maps and institutional affiliations.

\section{Author details}

'Department of Biochemistry and Molecular Biology, University of Nebraska Medical Center, Omaha NE-68022, USA. ²Buffet Cancer Center, University of Nebraska Medical Center, Omaha, NE, USA. ${ }^{3}$ Department of Surgery, Colorectal Service, Memorial Sloan Kettering Cancer Center, New York, NY, USA. ${ }^{4}$ Human Oncology and Pathogenesis Program at MSKCC, New York, NY, USA. ${ }^{5}$ Division of Biostatistics, University of Miami Miller School of Medicine, Miami, FL, USA. ${ }^{6}$ VA Nebraska-Western lowa Health Care System, Omaha, NE, USA.

\section{Received: 11 December 2017 Accepted: 29 June 2018}

Published online: 01 August 2018

\section{References}

1. Álvarez-Fernández M, Sánchez-Martínez R, Sanz-Castillo B, Gan PP, SanzFlores M, Trakala M, et al. Greatwall is essential to prevent mitotic collapse after nuclear envelope breakdown in mammals. Proc Natl Acad Sci U S A. 2013;110(43):17374.

2. Wang L, Luong VQ, Giannini PJ, Peng A. MASTL kinase, a promising therapeutic target, promotes cancer recurrence. Oncotarget. 2014;5(22): 11479-89.

3. Cundell Michael J, Bastos Ricardo N, Zhang T, Holder J, Gruneberg U, Novak B, et al. The BEG (PP2A-B55/ENSA/Greatwall) pathway ensures cytokinesis follows chromosome separation. Mol Cell. 2013;52(3):393-405.

4. Adhikari D, Liu K, Kaldis P. MASTL/PP2A regulate Cdk1 in ooycte maturation. Oncotarget. 2015;6(22):18734-5.

5. Hégarat N, Vesely C, Vinod PK, Ocasio C, Peter N, Gannon J, et al. PP2A/B55 and Fcp1 regulate Greatwall and Ensa Dephosphorylation during mitotic exit. PLoS Genet. 2014;10(1):e1004004.

6. Manchado E, Guillamot M, de Cárcer G, Eguren M, Trickey M, García-Higuera I, et al. Targeting mitotic exit leads to tumor regression in vivo: modulation by Cdk1, MASTL, and the PP2A/B55 phosphatase. Cancer Cell. 18(6):641-54.

7. Bhat AA, Pope JL, Smith JJ, Ahmad R, Chen X, Washington MK, et al. Claudin-7 expression induces mesenchymal to epithelial transformation (MET) to inhibit colon tumorigenesis. Oncogene. 2015;34(35):4570-80.
8. Zeng C, Pan F, Jones LA, Lim MM, Griffin EA, Sheline Yl, et al. Evaluation of 5-ethynyl-2'- deoxyuridine staining as a sensitive and reliable method for studying cell proliferation in the adult nervous system. Brain Res. 2010;1319:21-32.

9. Zaffaroni N, De Marco C, Villa R, Riboldi S, Daidone MG, Double JA. Cell growth inhibition, G2M cell cycle arrest and apoptosis induced by the imidazoacridinone C1311 in human tumour cell lines. Eur J Cancer. 2001;37(15):1953-62.

10. Lau WS, Chen T, Wong YS. Allyl isothiocyanate induces G2/M arrest in human colorectal adenocarcinoma SW620 cells through down-regulation of Cdc25B and Cdc25C. Mol Med Rep. 2010;3(6):1023-30.

11. Lee SH, Son SM, Son DJ, Kim SM, Kim TJ, Song S, et al. Epothilones induce human colon cancer SW620 cell apoptosis via the tubulin polymerization independent activation of the nuclear factor- kappaB/lkappaB kinase signal pathway. Mol Cancer Ther. 2007;6(10):2786-97.

12. Nakamura M, Tsuji N, Asanuma K, Kobayashi D, Yagihashi A, Hirata K, et al. Survivin as a predictor of cis-diamminedichloroplatinum sensitivity in gastric cancer patients. Cancer Sci. 2004;95(1):44-51.

13. Kamran M, Long ZJ, Xu D, Lv SS, Liu B, Wang CL, et al. Aurora kinase a regulates Survivin stability through targeting FBXL7 in gastric cancer drug resistance and prognosis. Oncogene. 2017;6(2):e298.

14. Kondo S, Shinomura Y, Kanayama S, Higashimoto Y, Kiyohara T, Zushi S, et al. Modulation of apoptosis by endogenous Bcl-xL expression in MKN-45 human gastric cancer cells. Oncogene. 1998;17(20):2585-91.

15. Shi WJ, Gao JB. Molecular mechanisms of chemoresistance in gastric cancer. World J Gastrointest Oncol. 2016;8(9):673-81.

16. Krausova M, Korinek V. Wnt signaling in adult intestinal stem cells and cancer. Cell Signal. 2014;26(3):570-9.

17. Kolligs FT, Bommer G, Goke B. Wnt/beta-catenin/tcf signaling: a critical pathway in gastrointestinal tumorigenesis. Digestion. 2002;66(3):131-44.

18. Olmeda D, Castel S, Vilaro S, Cano A. Beta-catenin regulation during the cell cycle: implications in G2/M and apoptosis. Mol Biol Cell. 2003;14(7): 2844-60.

19. Sarkar S, Mandal C, Sangwan R, Mandal C. Coupling G2/M arrest to the Wnt/beta-catenin pathway restrains pancreatic adenocarcinoma. Endocr Relat Cancer. 2014;21(1):113-25.

20. Spiteri C, Moses JE. Copper-catalyzed azide-alkyne cycloaddition: regioselective synthesis of 1,4,5- trisubstituted 1,2,3-triazoles. Angew Chem Int Ed Engl. 2010;49(1):31-3.

21. Balakrishnan A, Vyas A, Deshpande K, Vyas D. Pharmacological cyclin dependent kinase inhibitors: Implications for colorectal cancer. World J Gastroenterol. 2016;22(7):2159-64.

22. Malumbres M. Physiological relevance of cell cycle kinases. Physiol Rev. 2011;91(3):973-1007.

23. Voets $E$, Wolthuis RMF. MASTL is the human ortholog of Greatwall kinase that facilitates mitotic entry, anaphase and cytokinesis. Cell Cycle. 2010;9(17):3591-601.

24. Gharbi-Ayachi A, Labbe JC, Burgess A, Vigneron S, Strub JM, Brioudes E, et al. The substrate of Greatwall kinase, Arpp19, controls mitosis by inhibiting protein phosphatase 2A. Science. 2010;330(6011):1673-7.

25. Lorca T, Castro A. The Greatwall kinase: a new pathway in the control of the cell cycle. Oncogene. 2013;32(5):537-43.

26. Mochida S, Maslen SL, Skehel M, Hunt T. Greatwall phosphorylates an inhibitor of protein phosphatase $2 \mathrm{~A}$ that is essential for mitosis. Science. 2010;330(6011):1670-3.

27. Rogers S, Fey D, McCloy RA, Parker BL, Mitchell NJ, Payne RJ, et al. PP1 initiates the dephosphorylation of MASTL, triggering mitotic exit and bistability in human cells. J Cell Sci. 2016;129(7):1340-54.

28. OJ S, Meniel VS, Muncan V, Phesse TJ, Wilkins JA, Reed KR, Vass JK, Athineos $\mathrm{D}$, Clevers $\mathrm{H}$, Clarke AR. Myc deletion rescues Apc deficiency in the small intestine. Nature. 2007;446(7136):676-9.

29. Jorge Vera, Lydia Lartigue, Suzanne Vigneron, Gilles Gadea,Veronique Gire, Maguy Del Rio, Isabelle Soubeyran, Frederic Chibon, Thierry Lorca, and Anna Castro. Greatwall promotes cell transformation by hyperactivating AKT in human malignancies. eLife. 2015;4:e10115.

30. Jordan A, Hadfield JA, Lawrence NJ, McGown AT. Tubulin as a target for anticancer drugs: agents which interact with the mitotic spindle. Med Res Rev. 1998;18(4):259-96.

31. Concin N, Stimpfl M, Zeillinger C, Wolff U, Hefler L, Sedlak J, et al. Role of p53 in G2/M cell cycle arrest and apoptosis in response to gammairradiation in ovarian carcinoma cell lines. Int J Oncol. 2003;22(1):51-7.

32. White BD, Chien AJ, Dawson DW. Dysregulation of Wnt/beta-catenin signaling in gastrointestinal cancers. Gastroenterology. 2012;142(2):219-32. 
33. Polakis P. Wnt signaling in cancer. Cold Spring Harb Perspect Biol 2012;4(5): a008052.

34. Wu J, Zhang H, Xu C, Xu H, Zhou X, Xie Y, et al. TIPE2 functions as a metastasis suppressor via negatively regulating beta-catenin through activating GSK3beta in gastric cancer. Int J Oncol. 2016;48(1):199-206.

35. MacDonald BT, Tamai K, He X. Wnt/beta-catenin signaling: components, mechanisms, and diseases. Dev Cell. 2009;17(1):9-26.

36. Louis SF, Vermolen BJ, Garini Y, Young IT, Guffei A, Lichtensztejn Z, et al. CMyc induces chromosomal rearrangements through telomere and chromosome remodeling in the interphase nucleus. Proc Natl Acad Sci U S A. 2005;102(27):9613-8

37. Sheen JH, Woo JK, Dickson RB. C-Myc alters the DNA damage-induced G2/M arrest in human mammary epithelial cells. Br J Cancer. 2003;89(8): 1479-85.

38. Brabletz T, Herrmann K, Jung A, Faller G, Kirchner T. Expression of nuclear beta-catenin and c-Myc is correlated with tumor size but not with proliferative activity of colorectal adenomas. Am J Pathol. 2000; 156(3):865-70

39. Yochum GS, Sherrick CM, Macpartlin M. Goodman RH. A beta-catenin/TCFcoordinated chromatin loop at MYC integrates $5^{\prime}$ and $3^{\prime}$ Wnt responsive enhancers. Proc Natl Acad Sci U S A. 2010;107(1):145-50.

40. Sikora K, Chan S, Evan G, Gabra H, Markham N, Stewart J, et al. C-Myc oncogene expression in colorectal cancer. Cancer. 1987;59(7):1289-95.

41. Smith DR, Myint T, Goh HS. Over-expression of the c-Myc proto-oncogene in colorectal carcinoma. Br J Cancer. 1993;68(2):407-13.

42. Erisman MD, Scott JK, Watt RA, Astrin SM. The c-Myc protein is constitutively expressed at elevated levels in colorectal carcinoma cell lines. Oncogene. 1988;2(4):367-78.

43. Sipos F, Firneisz G, Muzes $G$. Therapeutic aspects of c-Myc signaling in inflammatory and cancerous colonic diseases. World I Gastroenterol. 2016; 22(35):7938-50.

44. Miller DM, Thomas SD, Islam A, Muench D, Sedoris K. C-Myc and cancer metabolism. Clin Cancer Res. 2012;18(20):5546-53.

45. Kugimiya N, Nishimoto A, Hosoyama T, Ueno K, Enoki T, Li TS, et al. The CMyc-ABCB5 axis plays a pivotal role in 5-fluorouracil resistance in human colon cancer cells. J Cell Mol Med. 2015;19(7):1569.

46. Amati B, Alevizopoulos K, Vlach J. Myc and the cell cycle. Front Biosci. 1998; 3:d250-68.

47. Berns K, Hijmans EM, Bernards R. Repression of c-Myc responsive genes in cycling cells causes G1 arrest through reduction of cyclin E/CDK2 kinase activity. Oncogene. 1997;15(11):1347-56.

48. Seth A, Gupta S, Davis RJ. Cell cycle regulation of the c-Myc transcriptional activation domain. Mol Cell Biol. 1993;13(7):4125-36.

49. Giles FJ, Cortes J, Jones D, Bergstrom D, Kantarjian H, Freedman SJ. MK0457, a novel kinase inhibitor, is active in patients with chronic myeloid leukemia or acute lymphocytic leukemia with the T315I BCR-ABL mutation. Blood. 2007;109(2):500-2.

50. Kikuchi A, Kishida S, Yamamoto H. Regulation of Wnt signaling by protein-protein interaction and post-translational modifications. Exp Mol Med. 2006;38(1):1-10

51. Sehdev V, Katsha A, Arras J, Peng D, Soutto M, Ecsedy J, et al. HDM2 regulation by AURKA promotes cell survival in gastric Cancer. Clin Cancer Res. 2014;20(1):76-86.

52. Katsha A, Soutto M, Sehdev V, Peng D, Washington MK, Piazuelo MB, et al. Aurora kinase a promotes inflammation and tumorigenesis in mice and human gastric Neoplasia. Gastroenterology. 2013;145(6):1312-22.

53. Katsha A, Arras J, Soutto M, Belkhiri A, El-Rifai W. AURKA regulates JAK2STAT3 activity in human gastric and esophageal cancers. Mol Oncol. 2014; 8(8):1419-28.

54. Mitsiades CS, Mitsiades N, Koutsilieris M. The Akt pathway: molecular targets for anti-cancer drug development. Curr Cancer Drug Targets. 2004;4(3):235-56.

55. Pap M, Cooper GM. Role of glycogen synthase kinase-3 in the phosphatidylinositol 3-kinase/Akt cell survival pathway. J Biol Chem. 1998; 273(32):19929-32.

56. Sourbier C, Lindner V, Lang H, Agouni A, Schordan E, Danilin S, et al. The phosphoinositide 3- kinase/Akt pathway: a new target in human renal cell carcinoma therapy. Cancer Res. 2006;66(10):5130-42.

\section{Ready to submit your research? Choose BMC and benefit from:}

- fast, convenient online submission

- thorough peer review by experienced researchers in your field

- rapid publication on acceptance

- support for research data, including large and complex data types

- gold Open Access which fosters wider collaboration and increased citations

- maximum visibility for your research: over $100 \mathrm{M}$ website views per year

At BMC, research is always in progress.

Learn more biomedcentral.com/submissions 